\title{
Work-life balance, job satisfaction and retention: Turnover intentions of professionals in part-time study
}

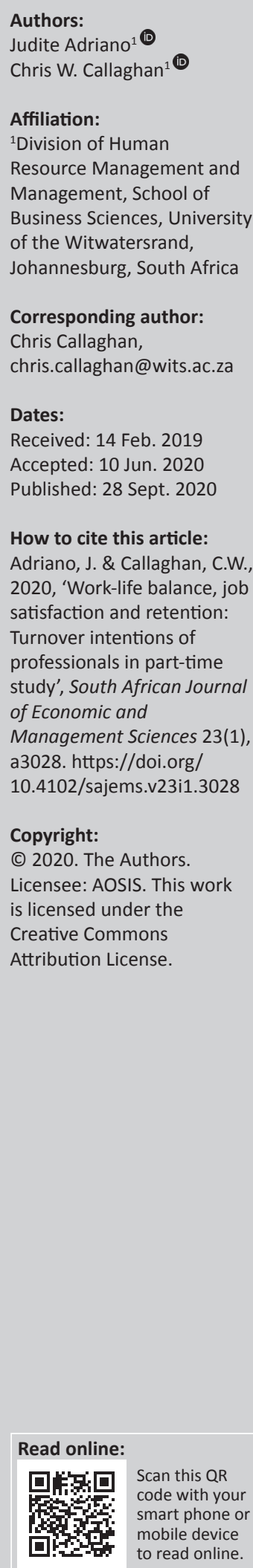

Background: Undertaking degree studies while working can provide life-changing career opportunities. These studies, however, can introduce substantial work-life balance conflict, particularly for those with family responsibilities, with important implications for retention.

Aim: The aim of this study is to test theory that predicts the effects of certain moderating and mediated influences on the relationship between work-life balance conflict and turnover intentions of professional staff undertaking evening degree classes at a selected South African university.

Setting: The sample was drawn from a large university in Gauteng, South Africa.

Methods: This study applies Hayes's PROCESS methodology to test the moderating effects of age, gender, numbers of dependent children, social support, engagement and levels of stress on the relationship between work-life conflict and turnover intentions. Further tests of mediation are performed to test the mediating influence of job satisfaction on the same relationship.

Results: Findings suggest a unique configuration of moderating and mediation influences relating to the work-life balance conflict for this cohort, particularly for those with dependent children. Those with more children who experience higher levels of work-life balance conflict are less likely to display higher turnover intentions. Individuals with higher levels of social support are however more likely to report higher levels of turnover intentions.

Conclusion: These results support the conclusion that the relationships between work-life conflict and turnover intentions for working individuals undertaking evening degree classes in this context, display a different configuration of moderating influences from those expected in general working populations. Employers and other stakeholders should pay particular attention to these implications so as to ensure retention of scarce skills.

Keywords: turnover intentions; intent to quit; withdrawal intentions; work-life balance, retention, staff development; human resources.

\section{Introduction}

When an organisation loses employees, their knowledge is lost as well. This loss of knowledge can be at cost to an organisation's competitive advantage (Omotayo 2015; Sarra, Benabou \& Tabeti 2013). The loss of highly skilled employees can result in the loss of tangible sunk costs, related to recruiting, hiring and training, and intangible costs, associated with reduced productivity, loss of knowledge and the loss of employee morale (Kantor \& Crosser 2016). Given the direct threat of voluntary exit to inimitable tacit organisational knowledge stocks (Kinnear \& Sutherland 2000), and to competitive advantage (Omotayo 2015; Sarra et al. 2013), knowledge of what contributes to turnover intentions is of particular importance across contexts in today's competitive business environments.

The retention of skilled professionals is therefore a dominant concern of organisations due to the high turnover rates they are facing globally, as well as increased competition in recruitment (Samuel \& Chipunza 2009).

Given the costs to organisations of the lack of this knowledge, and resultant uncertainty, it is necessary for human resource practitioners to turn to theory to better understand these relationships. Knowledge of the relative salience of the demographic, social and organisational influences on the relationship between work-life balance and employee attrition is therefore an important topic of research across different contexts of work. This study seeks to extend previous work to better understand how theory derived from general work contexts predicts 
certain moderating influences on the relationships between work-life conflict and the turnover intentions of employed persons that are engaged in evening degree studies at a large South African university.

Social exchange theory suggests that employee assessments of the quality of their interchange relationships with their organisations are related to their well-being and commitment to the organisation (Avanzi et al. 2014). Such interchange relationships may however not be independent from demands placed on them by family life and the pressures of part-time study undertaken for work-related reasons. Indeed, decreases in an individual's work-life balance might work through the job dissatisfaction channel to contribute to withdrawal intentions and intent to quit, thus thwarting a firm's retention strategies. Furthermore, the strength of the contribution of work-life balance to employee retention may be influenced by certain demographic characteristics such as age, gender and number of dependent children.

Similarly, the strength of this relationship may also be influenced by the social support an individual receives, as well as organisational factors such as engagement and stress, which may be experienced more intensely, or even unequally, in a societal context of resource scarcity (Papageorgiou \& Callaghan 2014).

Maintaining a work-life balance or successfully managing conflict between employee work and non-work-life, including family life (Grzywacz \& Carlson 2007), is thus an important dimension of the reciprocal relationship between an individual and the organisation. Job satisfaction relates to the extent to which an individual is satisfied with current work roles associated with the job (Oosthuizen, Coetzee \& Munro 2016).

Levels of job satisfaction are therefore key to employee retention (Dockel, Basson \& Coetzee 2006).

There is thus agreement in the literature on the importance of work-life balance conflict, and of the effect of job satisfaction as a channel through which deficits in the work-life balance can contribute to voluntary turnover.

What is less clear is the salience of these relationships for employees that are undertaking degree studies evening classes in the South African context of Gauteng, for the following reasons.

Firstly, in the fast-paced context of the country's commercial heartland, work-related work-life balance conflict (WLBC) pressures might be the most intense in the country. Having achieved democracy in 1994, the country faces legacy challenges related to disadvantage and inequality, which make the attainment of degree education a necessary condition for career advancement in certain fields. Given the country's historical legacy of educational inequality, many in formal employment were denied opportunities for formal higher education.
The part-time degree studies programmes of large Gauteng universities therefore have an important role in addressing these legacy effects. Undertaking degree studies for career progression may, however, have an important influence on an individual's work-life balance. The influence of high levels of work-life conflict may be compounded if one's earlier schooling was compromised by such legacy effects. Knowledge of the consequences of these work-life balance effects, related to part-time studies on intent to quit, is arguably of particular importance in such a context. Similarly, given the differences in careers that are related to differences in subject choices (Papageorgiou et al. 2014), what is lacking is knowledge of these relationships that generalise across an entire sample of students.

Secondly, what is not clear in the literature is the extent to which undertaking degree studies (where classes are held in the evenings, unlike distance education which is more flexible in its time requirements) while maintaining formal employment, and (in some instances) managing a family and family life, might alter the conditions under which work-life balance and retention relate to each other. Whereas the literature relating to general working contexts offers a theoretical model of what these relationships are across contexts, what is lacking in the South African literature is a model of these relationships at this time, for this particular cohort. Of particular interest are the moderating roles of demographical variables like age, gender and number of dependent children on the relationship between work-life balance and voluntary exit, or an individual's intent to leave their employment, or intent to quit.

Similarly, what is also not well understood about this cohort is the potential role of satisfaction as a mediator of the relationship between work-life balance and intent to quit. Under certain conditions, the pressures of having a family to provide for, together with those of part-time degree studies which require evening classes might create dissatisfaction, but it is unclear under which conditions this might contribute to employee attrition. Indeed, under certain conditions, dissatisfaction might not influence an individual's turnover intentions, and might not mediate the relationship between work-life conflict and turnover intentions at all. Such a result might have particular importance for employers in this context.

Thirdly, what is also lacking in this context is knowledge of the role of social support, as well as organisational factors such as engagement and stress, in the relationship between work-life balance and intent to quit for this cohort. Such knowledge may provide useful insights for those who are in a position to provide societal support to those undertaking part-time studies while working. These insights might also be useful to employers seeking to support these staff members, and may contribute to more effective retention strategies.

Given the importance of this knowledge in this context, the study poses the question: under what conditions does work-life balance contribute differently to employee withdrawal cognitions 
for this cohort of individuals? In doing so, this work therefore seeks to contribute to the literature on work-life balance and turnover intentions, such as that by Du Plooy and Roodt (2013) which seeks to better understand certain moderating effects and their influence on turnover intentions in the South African context. This work has relevance even to research on commitment from the broader regional context (Chinomona, Chinomona \& Joubert 2013). In seeking to contribute to the literature, this study therefore seeks to offer useful contextual understanding, and a more holistic perspective (Goldman \& Callaghan 2015), of how direct and interactive effects manifest in the specific and unique context of employees who face work-life conflict from the pressures of work and study in this context. Having introduced the focus of the study, it proceeds as follows. Firstly, theory is reviewed and hypotheses are derived for testing. Next, the methods of the research are introduced. Results are then reported and discussed. The article then concludes.

\section{Theory and hypotheses}

Work-life balance has been defined as the degree to which there is equitable satisfaction and engagement relating to an employee's work and family roles (Greenhaus, Collins \& Shaw 2003). Certain studies have failed to find an empirical relationship between work-life balance and turnover intentions (Riley 2006), whereas others have found worklife balance to directly affect turnover rates of employees and their turnover intentions (Moore 2007). Similarly, higher levels of work-family conflict (Schilling 2014) have also been found to increase intent to quit. Although studies have found mixed results in different settings, given the context of the cohort tested here, who have evening degree classes in addition to working and, in many cases, family responsibilities, Hypothesis 1 is derived: increases in worklife balance conflict are significantly associated with increases in intent to quit.

Noor (2011) defines work-life balance as the efficient management of certain 'balancing acts' related to work, family and other activities. Individuals in full-time employment who undertake degree studies on evening programmes often have to balance work activities with those of academic studies. Older individuals might have been disproportionately exposed to the educational legacy effects of the pre-democracy era. If older individuals experience greater difficulties in part-time degree studies, this might reduce their work-life balance relative to those who are younger. Similarly, the length of time out of school might pose greater adjustment pressures, which might be exacerbated by greater family commitments.

On the other hand, those older in this cohort might have more experience in managing such pressures, and might in certain cases even have a motivational advantage. What is not clear, however, is whether older or younger individuals are relatively more vulnerable to withdrawal cognitions when their work-life balance is disrupted or reduced. It is not clear if older employees, in this specific cohort, with greater family commitments remain with a firm irrespective of differences in job satisfaction associated with work-life pressures. Whereas many of these relationships can be predicted, using a general theoretical model drawn across work contexts, we suggest that this cohort is not typical of general workers across contexts, given the unique historical context of the country which may have resulted in a new paradigm of work post 1994. On the basis of this logic, Hypothesis 1.a is derived: higher work-life balance conflict may be less likely to contribute to withdrawal intentions for older employees in part-time degree studies.

Boundary theory predicts that inter-role conflict can be reduced by adequately managing work and non-work commitments, through effective boundary management, or through the maintenance of temporal, physical, as well as psychological borders (Clark 2000). Notwithstanding attempts to manage it through boundary management, interrole conflict can take the form of work-family conflict on account of either interference from family with work, or interference from work with family. Work-family conflict can result from time-based, strain-based and behaviourbased conflict (Greenhaus \& Beutell 1985). Behaviour-based conflict refers to clashes in behaviour, when certain behaviours, deemed appropriate within the workplace context (for example assertiveness) can, in the family context, produce tension (Greenhaus \& Beutell 1985). Time-based strain might be particularly problematic if gender roles place a disproportionate (and unfair) amount of time pressure on women (associated with family responsibilities, or the maintenance of a home, even without dependent children). It is not clear, however, what the extent is to which these family pressures differ by gender in their effect on the influence of work-life balance on withdrawal intentions, in this specific cohort. If women face gender-discriminatory burdens in family life, this might contribute to work-life balance conflict, but the extent to which this transmits to withdrawal cognitions is not clear in this context. Hypothesis 1.b is therefore offered: the relationship between work-life balance and intent to quit is moderated by gender.

According to spillover theory, excessive time demands in either the family or work domains can result in spillover from family to work or from work to family (Edwards \& Rothbard 2000). Nevertheless, an individual with more dependent children might be less risk-taking in their job-changing behaviour. On this basis, Hypothesis 1.c is derived: the relationship between work-life balance conflict and intent to quit may be weakened when an individual has more dependent children.

Although time-based inter-role conflict theory suggests certain negative relationships between different roles, another theory suggests that these relationships can also be positive (Pradhan 2016). Carlson et al. (2006) suggest two mechanisms through which work-family enrichment can occur. The instrumental mechanism refers to conditions where resources attained in one role instantly enhance performance in a different role. The affective mechanism 
refers to instances where work-family enrichment transpires incidentally through the impact of a positive outcome. Social support, for example deriving from family and other social roles, might contribute to performance in other realms, but can also reduce the reliance of an individual on a job role that they are dissatisfied with continuing in. Hypothesis 1.d is therefore derived: the relationship between an increase in worklife balance conflict and intent to quit is increased under conditions of higher social support.

Similarly, various studies have confirmed that certain experiences in a working environment can augment family life (Pradhan 2016). Organisational factors that increase engagement may also reduce the contributions of lower work-life balance to increased withdrawal cognitions, hence Hypothesis 1.e: the relationship between an increase in work-life balance conflict and intent to quit is reduced at higher levels of engagement.

An increase in withdrawal cognitions can result from job dissatisfaction, as well as from decreased work-life balance. Job dissatisfaction might however act as a primary channel through which decreases in work-life balance contribute to withdrawal intentions. Theory offers certain plausible reasons why this might be so.

Dissatisfaction with work-life balance pressures might be amplified in a family context, if psychological strain (stress) on an individual due to increased time and work pressures (such as those associated with the demands of evening classes that compound work commitments) extends to a partner or other members of a family, as predicted by crossover theory (Pradhan 2016). It bears noting that this cohort was also exposed to the FeesMustFall protests and its aftermath, the experience of which might have been stressful for certain students at this institution (Jogee, Callaghan \& Callaghan 2018). Similarly, stress might be 'amplified' through the same mechanism suggested by crossover theory, if an individual's stress has an influence on other members of the family. Hypothesis 1.f is therefore offered: the relationship between increases in work-life balance conflict and intent to quit is strengthened at higher levels of stress.

Job matching theory is built around the notion that fresh information about the job match, is what results in turnover (Mincer \& Jovanovic 1979). According to this perspective, before commencing a job, employees may have 'imperfect' information and as a result may have uncertainties regarding the value they gain as their job tenure increases. Similarly, withdrawal cognitions are a function of this match, because the identification of a mismatch in the employment relationship often occurs at the beginning rather than towards the end (Mincer \& Jovanovic 1979). Therefore, the longer an individual is with an employer, the less likely it may be for an employee to quit for this reason. Key to retention is therefore the subjective job satisfaction of the employee, which may be a function of the extent to which expectations are met in the workplace context.
Indeed, satisfaction is key to the retention of knowledgeable workers (Coetzee \& Martins 2007; Dockel et al. 2006). Job satisfaction is defined here as a general affectional inclination of individuals toward work roles that they currently occupy (Oosthuizen et al. 2016), which accords with Weiss, Dawis and England's (1967) definition of job satisfaction as the extent to which a person accomplishes and sustains correspondence with the surroundings fulfilling their extrinsic and intrinsic desires. Low levels of job satisfaction result in augmented intention to leave among employees, intensifying an individual's turnover intention (Martin \& Roodt 2008; Özbağ \& Ceyhun 2014).

Job satisfaction has been found to partially (Noor 2011) and fully (Fayyazi \& Aslani 2015) mediate the relationship between WLBC and turnover intentions in certain contexts. Similarly, job satisfaction has also been found to mediate the relationship between family-to-work conflict and turnover intentions (Riley 2006).

Other research has, however, found job satisfaction to not mediate the relationship between work-family conflict and turnover intentions (Özbağ \& Ceyhun 2014). The action of job satisfaction as a mediator of the relationship between WLBC and turnover intentions might therefore be context specific. Hence we derive Hypothesis 2: job satisfaction mediates the relationship between work-life balance conflict and turnover intentions in this context. Having reviewed certain relevant literature, and having derived hypotheses for testing, the methods undertaken to test these hypotheses are now discussed.

\section{Methods}

The study applied a cross-sectional quantitative research design. Questionnaires were used to collect data from a cohort of employed degree students taking evening classes. The sample was drawn from a large university in Gauteng, South Africa. We undertook a quantitative study as certain theoretical frameworks already exist that link the variables. However, these theoretical frameworks, and examples of previous work, were drawn from the broader work context, and it was necessary to test the specific theory in this particular context, with regard to this specific cohort. Quantitative methods were chosen as they allow for the summarisation of large amounts of information and are well suited to comparative analysis (Kruger 2003).

A population refers to people who have certain attributes and are of concern to an investigator. The population for this study comprised the general population of full-time employees employed within various organisations across industries in Gauteng that were also studying in university part-time evening degree programmes. An attempt was made to sample the entire part-time studies population of the university. A census sampling strategy was therefore applied. Both email and hard copy questionnaires were used to sample responses. 
Refusals were unconditionally respected. A sampling protocol was followed to ensure consistency in the respondents' experience of the data sampling process. Notwithstanding a relatively high number of refusals, 315 usable responses were ultimately attained. This amounted to a response rate of about $29 \%$ of the estimated 1100 students in the evening studies programme. An outline of the sample in terms of factual and demographic data is provided in Table 1 . The majority of respondents are in the age range of 20 to 35 years $(71 \%)$, with a sizable portion between the ages of 36 and 50 (20\%). Women comprise the majority, as do those who are unmarried. Black employees make up $67 \%$ of the sample. The racial breakdown broadly reflects the demographics of the province, Gauteng, providing support for the representativeness of the sample. Of the total respondents, $52 \%$ indicated having dependent children. Over half the sample was therefore expected to be managing three-way work-life balance roles that extended to studies, work and family responsibilities.

We used the principles of reliability and validity to guide the research process. Reliability, or consistency, was assessed though Cronbach's alpha tests. Piloting was also used to ensure reliability and validity. The scales and their sources are now discussed.

\section{Turnover intention}

Roodt's (2004) unpublished Turnover Intention Scale was used to measure the intentions an employee has to either stay with or leave an organisation. The scale is also used by Jacobs and Roodt (2008). It consists of 14 items measured using a seven-point Likert scale which ranges from 'never' to 'always'. The scale has previously been validated in the South African context, attaining a Cronbach's alpha of 0.80 (see Bothma \& Roodt 2013). In this study, its value is 0.84 .

\section{Work-life balance}

Haslam et al.'s (2015) Work-Family Conflict Scale (WAFCS) was utilised to assess WLBC. The scale consists of 10 items in which five items are used to measure family-to-work conflict and the remaining five items are used to assess work-tofamily conflict. These measures apply a seven-point scale to measure participants' agreement with statements, varying from 'very strongly disagree' to 'very strongly agree'. The alpha in this study was 0.877 .

\section{Job satisfaction}

The Minnesota Satisfaction Questionnaire (MSQ) has been widely used to measure job satisfaction (Weiss et al. 1967). The scale contains 20 items that measure individuals' intrinsic, extrinsic and general levels of satisfaction with the use of a five-point Likert-type scale, ranging from 'very dissatisfied' to 'very satisfied'. On account of piloting, 18 of the 20 items were retained, with the remaining items measuring a composite of extrinsic and intrinsic motivation. The incorporation of both intrinsic and extrinsic motivation was taken to be important in that this captured an
TABLE 1: Biographical and demographic profile of respondents $(N=315)$.

\begin{tabular}{|c|c|c|c|}
\hline Item & Group & Frequency $(n)$ & Percentage (\%) \\
\hline \multirow[t]{5}{*}{ Age } & $<20$ & 1 & 0 \\
\hline & $20-35$ & 223 & 71 \\
\hline & $36-50$ & 63 & 20 \\
\hline & $>50$ & 6 & 2 \\
\hline & Prefer not to say & 22 & 7 \\
\hline \multirow[t]{3}{*}{ Gender } & Male & 116 & 37 \\
\hline & Female & 198 & 63 \\
\hline & Prefer not to say & 1 & 0 \\
\hline \multirow[t]{5}{*}{ Marital status } & Single & 188 & 60 \\
\hline & Married & 97 & 31 \\
\hline & Separated & 4 & 1 \\
\hline & Divorced & 17 & 5 \\
\hline & Other & 9 & 3 \\
\hline \multirow[t]{5}{*}{ Population group } & African & 210 & 67 \\
\hline & Coloured & 29 & 9 \\
\hline & White & 48 & 15 \\
\hline & Indian & 24 & 8 \\
\hline & Other & 4 & 1 \\
\hline \multirow[t]{7}{*}{ Highest qualification } & Matric certificate & 112 & 36 \\
\hline & Other & 78 & 25 \\
\hline & Bachelor's degree & 81 & 26 \\
\hline & Honours & 26 & 8 \\
\hline & Master's & 6 & 2 \\
\hline & $\mathrm{PhD}$ & 1 & 0 \\
\hline & Prefer not to say & 11 & 3 \\
\hline \multirow[t]{6}{*}{ Years of experience } & $<1$ & 1 & 0 \\
\hline & $1-2$ & 38 & 12 \\
\hline & $3-5$ & 77 & 25 \\
\hline & $6-10$ & 105 & 33 \\
\hline & $>10$ & 82 & 26 \\
\hline & Prefer not to say & 12 & 4 \\
\hline \multirow{4}{*}{$\begin{array}{l}\text { Number of } \\
\text { dependents }\end{array}$} & None & 146 & 47 \\
\hline & $1-3$ & 154 & 49 \\
\hline & $>3$ & 11 & 3 \\
\hline & Prefer not to say & 4 & 1 \\
\hline \multirow{7}{*}{$\begin{array}{l}\text { Industry } \\
\text { representation }\end{array}$} & Finance & 43 & 14 \\
\hline & Banking & 21 & 7 \\
\hline & IT & 15 & 5 \\
\hline & Insurance & 10 & 3 \\
\hline & Education & 17 & 5 \\
\hline & Government & 11 & 3 \\
\hline & Media & 11 & 3 \\
\hline
\end{tabular}

individual's satisfaction with a broad range of influences. This scale has previously been used in the South African context with acceptable reliability (for example, by Visser and Coetzee 2005, who obtained an alpha of 0.88 for these items). The alpha for this item in this study was 0.877 .

\section{Stress and engagement}

The Subjective Job Stress Scale (SJSS) was used to measure individual job stress (Motowidlo, Packard \& Manning 1986). This scale included Likert-type scale items that sampled responses ranging from 'strongly disagree' to 'strongly agree'. The alpha for this scale was 0.80. The Employment Engagement Survey (Wilson 2009) was utilised to measure employee engagement. These items have demonstrated reliability in Wilson's previous study, with an alpha of 0.77 . The alpha found for this study is 0.80 . 


\section{Perceived social support}

Zimet et al.'s (1988) Multidimensional Scale of Perceived Social Support (MSPSS) was used to measure the degree to which a person recognises social support from significant others, family and friends. The scale consists of 12 Likerttype items. It has been found to be reliable in other contexts, such as an alpha of 0.83 in the African context (Nakigudde et al. 2009), 0.73 in a cohort of war veterans (Wilcox 2010) and 0.91 in the context of Thailand (Wongpakaran, Wongpakaran \& Ruktrakul 2011). In this study, the alpha value was 0.924 .

\section{Ethical consideration}

This study adhered to the various ethical guidelines. An Ethics Clearance Certificate was issued after the study was approved by the University of Witwatersrand's ethics committee (protocol number CBUSE/1233, 25 May 2017). The confidentiality and anonymity of the research participants was respected. The research respondents were made aware that their participation was voluntary, and respondents were given the freedom to withdraw at any given time. Most importantly, informed consent was obtained prior to the participation of the respondents. Ethical standards were maintained throughout the processes of the study.

\section{Data analysis}

Univariate analysis was performed to check for missing values. The biographical and demographic profile of respondents is reported in Table 1. Descriptive statistics are reported in Table 2. Multiple linear regressions were utilised to test hypothesised direct, mediated and moderated relationships. Hypothesis testing was performed using a significance level of $5 \%$, or $\alpha=0.05$. The PROCESS macro for SPSS (Hayes 2013) was used for analysis. Assumptions of the regression analysis process were assessed, including the assumptions of normality of residuals, homoscedasticity and multicollinearity.

Residual plots were inspected, and histograms were plotted for residual values. On the basis of these plots the residual distribution was taken to approximate normality. This suggested little evidence of heteroscedasticity. Variance inflation tests were performed to test for multicollinearity. These values were also taken to provide reasonable evidence that multicollinearity was not a threat to the interpretation of the results. Overall, for most of the variables, skewness was within the acceptable limits of \pm 2 (Field 2000).

In order for nominal variables to be included in the regression analysis, this study made use of dummy variables, which are often used in the investigation of the influence of categorical variables (Holgersson, Nordström \& Öner 2014; Yip \& Tsang 2007). Linear regression models can only be used when there is a quantitative dependent variable, as well as quantitative continuous or dummy predictive variables (Çilan \& Can; 2014; Gujarati \& Porter 2009).

Therefore, seeing that many predicative variables in surveys are often categorical, they need to be converted to dummy variables in order to use traditional linear regression models. For this reason, the creation of dummy variables is acceptable practice in regression analysis (Gujarati \& Porter 2009).

Stevens (1946) outlines the four types of scales that include interval, nominal, ordinal and ratio data. The various types of scales can be distinguished by the group of transformations each can be subject to without losing empirical information (Stevens 1946). According Gujarati (2011), nominal, ordinal, interval and ratio scales are typically used in quantitative analysis.

\section{Results and discussion}

The results of the hypothesis testing are now reported and discussed:

H1: Increases in work-life balance conflict are significantly associated with increases in intent to quit.

Model 1 includes the covariate factors, namely age, gender and race dummies, and number of dependents.

Table 3 reports the results of the tests of the hypotheses. After including our variable of interest, WLBC, its coefficient is significant ( $p=0.0001$ ), over and above the influence of the covariates. The null hypothesis is rejected. These results differ from those of Riley (2006) who found no relationship between work-life balance and turnover intention. These findings suggest that, at least in terms of this core relationship,

TABLE 2: Descriptive statistics.

\begin{tabular}{|c|c|c|c|c|c|c|c|c|}
\hline \multirow[t]{2}{*}{ Variable } & \multicolumn{4}{|c|}{ Statistic } & \multicolumn{2}{|c|}{ Skewness } & \multicolumn{2}{|c|}{ Kurtosis } \\
\hline & Minimum & Maximum & Mean & Standard deviation & Statistic & Standard error & Statistic & Standard error \\
\hline Age & 19 & 57 & 32.43 & 7.133 & 0.860 & 0.142 & 0.700 & 0.284 \\
\hline Gender & 0 & 1 & 0.63 & 0.483 & -0.544 & 0.138 & -1.715 & 0.274 \\
\hline Years of employment & 0.00 & 40.00 & 8.629 & 6.443 & 1.400 & 0.138 & 2.463 & 0.276 \\
\hline Number of children & 0 & 7 & 1.05 & 1.246 & 1.284 & 0.138 & 1.983 & 0.276 \\
\hline Highest qualification & 1 & 7 & 2.81 & 2.024 & 0.771 & 0.140 & -1.095 & 0.278 \\
\hline Stress & 1.00 & 5.00 & 3.308 & 0.962 & -0.179 & 0.137 & -0.729 & 0.274 \\
\hline Engagement & 1.750 & 6.00 & 4.155 & 0.938 & -0.216 & 0.137 & -0.508 & 0.274 \\
\hline Social support & 1.00 & 7.00 & 5.301 & 1.221 & -0.927 & 0.137 & 0.962 & 0.274 \\
\hline Work-life balance & 1.00 & 6.6 & 3.018 & 1.231 & 0.255 & 0.137 & -0.383 & 0.274 \\
\hline Turnover intention & 1.00 & 6.57143 & 4.224 & 1.165 & -0.381 & 0.137 & -0.305 & 0.274 \\
\hline
\end{tabular}


TABLE 3: Regression coefficients for Hypothesis 1.

\begin{tabular}{|c|c|c|c|c|c|c|c|c|c|c|c|}
\hline \multirow[t]{2}{*}{ Model } & \multirow[t]{2}{*}{ Coefficients $\dagger$} & \multicolumn{2}{|c|}{ Unstandardised coefficients } & \multirow{2}{*}{$\begin{array}{c}\text { Standardised } \\
\text { coefficients: Beta }\end{array}$} & \multirow[t]{2}{*}{$t$} & \multirow[t]{2}{*}{ Significance } & \multicolumn{3}{|c|}{ Correlations } & \multicolumn{2}{|c|}{ Collinearity statistics } \\
\hline & & Beta & Standard error & & & & Zero-order & Partial & Part & Tolerance & VIF \\
\hline \multirow[t]{7}{*}{1} & (Constant) & 4.315 & 0.390 & - & 11.067 & 0.000 & - & - & - & - & - \\
\hline & Age & -0.019 & 0.011 & -0.113 & -1.703 & 0.090 & -0.076 & -0.101 & -0.099 & 0.766 & 1.305 \\
\hline & Gender & 0.125 & 0.143 & 0.052 & 0.876 & 0.382 & 0.030 & 0.052 & 0.051 & 0.967 & 1.034 \\
\hline & Indian & 0.233 & 0.301 & 0.053 & 0.776 & 0.438 & -0.023 & 0.046 & 0.045 & 0.722 & 1.386 \\
\hline & Coloured & 0.389 & 0.284 & 0.097 & 1.373 & 0.171 & 0.018 & 0.081 & 0.080 & 0.683 & 1.465 \\
\hline & African & 0.425 & 0.194 & 0.172 & 2.189 & 0.029 & 0.125 & 0.129 & 0.128 & 0.548 & 1.825 \\
\hline & Number of children & 0.089 & 0.064 & 0.095 & 1.397 & 0.164 & 0.070 & 0.083 & 0.081 & 0.731 & 1.368 \\
\hline \multirow[t]{7}{*}{2} & (Constant) & 2.849 & 0.374 & - & 7.623 & 0.000 & - & - & - & - & - \\
\hline & Age & -0.018 & 0.009 & -0.111 & -1.903 & 0.058 & -0.076 & -0.113 & -0.097 & 0.766 & 1.305 \\
\hline & Gender & 0.181 & 0.125 & 0.075 & 1.451 & 0.148 & 0.030 & 0.086 & 0.074 & 0.965 & 1.036 \\
\hline & Indian & 0.194 & 0.262 & 0.044 & 0.738 & 0.461 & -0.023 & 0.044 & 0.038 & 0.721 & 1.386 \\
\hline & Coloured & 0.546 & 0.248 & 0.136 & 2.201 & 0.029 & 0.018 & 0.130 & 0.112 & 0.680 & 1.471 \\
\hline & African & 0.543 & 0.170 & 0.220 & 3.197 & 0.002 & 0.125 & 0.187 & 0.163 & 0.545 & 1.835 \\
\hline & Work-life balance & 0.463 & 0.049 & 0.489 & 9.470 & 0.000 & 0.469 & 0.491 & 0.482 & 0.969 & 1.032 \\
\hline
\end{tabular}

$\dagger$, Dependent variable: Turnover intentions.

these results have much in common with those in the broader context of working relationships.

Only three demographic variables make a unique statistically significant contribution to the model, namely age, race (black and coloured), as well as our predictor variable, WLBC. In the first model, Black employees report significantly higher turnover intentions when WLBC is not included in the model, but when included, both black and coloured employees are associated with higher levels of turnover intentions.

Older employees report significantly lower turnover intentions, which accords with the literature (see Martin \& Roodt 2008). Gender is not significant, however, in its direct association with withdrawal cognitions.

H1.a: Higher WLBC may be less likely to contribute to withdrawal intentions for older employees in part-time degree studies.

The Hayes process model was used to test the significance of the interaction term of age and WLBC, which was not found to be significantly associated with turnover intentions $(p<0.216)$. The model was tested with the inclusion of covariate effects, so as to ensure that the test was not confounded by these other influences.

At low levels of WLBC there is little difference between younger and older individuals (Figure 1), but at higher levels of WLBC, older employees seem to have marginally higher levels of turnover intentions. This result accords with studies that have not found any moderating effects of age in the prediction of turnover intention. For example, age has been found to fail to moderate certain relationships in workplace contexts, such as those between organisational embeddedness and turnover intentions (Peltokorpi, Allen \& Froese 2015), but age has been found to moderate relationships predicting turnover intentions (Du Plooy \& Roodt 2013; Hellman 1997) in other settings. These findings suggest the importance of context, in that age has a direct and decreasing influence on turnover intentions but does not affect the relationship between WLBC and withdrawal intensions in this setting.

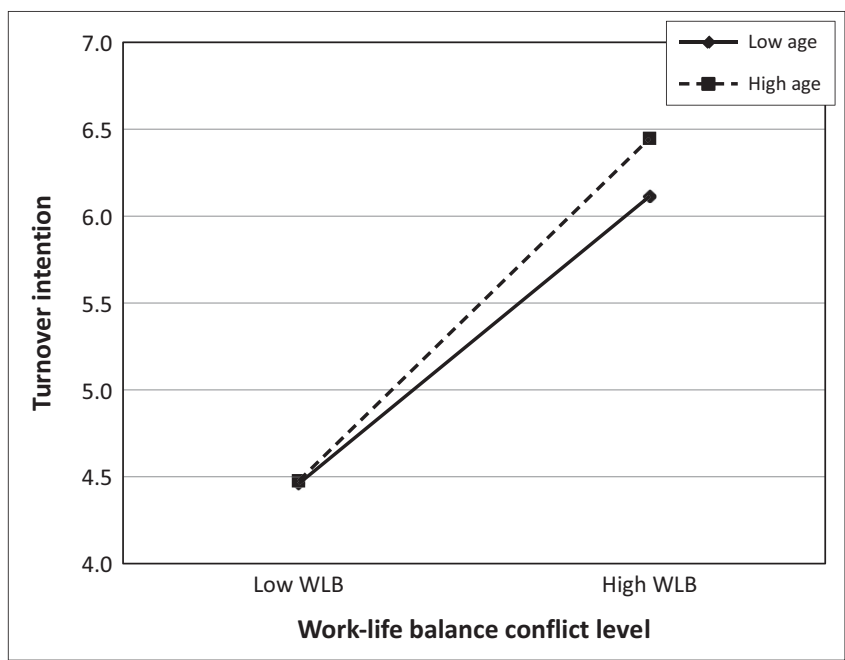

WLB, Work-life balance conflict.

FIGURE 1: Age as a moderator on work-life balance conflict-turnover intention relationship (two-way interaction).

H1.b: The relationship between work-life balance and intent to quit is moderated by gender.

The interaction effect between gender and WLBC (Figure 2) is not significant $(p=0.935)$.

Women have marginally higher turnover intentions than men, both at low and high levels of WLBC. The interaction effect is not significant, however, suggesting that men and women experience these relationships similarly in this context.

The finding is however at odds with various studies that found moderating effects of gender in the prediction of the turnover intentions of employees (Cotton \& Tuttle 1986; Peltokorpi et al. 2015), but is in line with other studies that have failed to find gender to moderate predictors of the turnover intentions, as well as to moderate the relationship between work-life balance and turnover intentions (Du Plooy \& Roodt 2013). This finding highlights the contextual relevance of gender as a moderator of these relationships. 
The majority of respondents are female, constituting $63 \%$ of the sample. A large portion of the sample (33\%) reported having 6-10 years of experience. The majority also reported being single $(60 \%)$, the largest group coming from the banking and finance industries (21\%). These demographic characteristics suggest that many individuals in this context might be seeking to qualify before starting a family. These results contribute to the literature on gender differences in university-related environments (Fatoki 2015).

H1.c: The relationship between WLBC and intent to quit may be weakened when an individual has more dependent children.

The interaction effect of WLBC and numbers of dependent children is significantly associated with the intent to quit $(p=0.002)$, net of differences associated with age, race and gender. As shown in Figure 3, individuals with fewer dependent children are more likely to quit, both at low and high levels of WLBC. The difference between these groups is

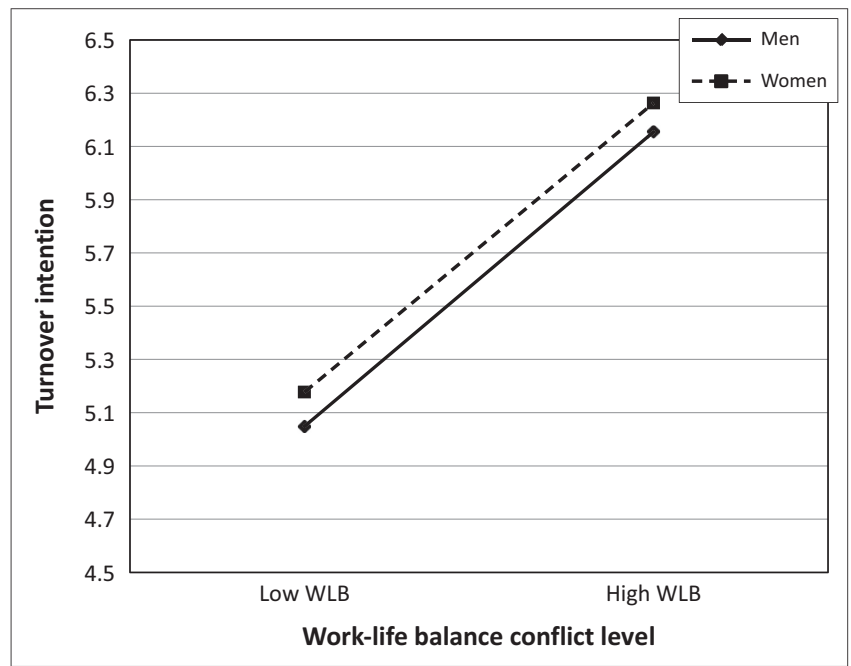

WLB, Work-life balance conflict.

FIGURE 2: Gender as a moderator on the work-life balance-turnover intention relationship (two-way interaction).

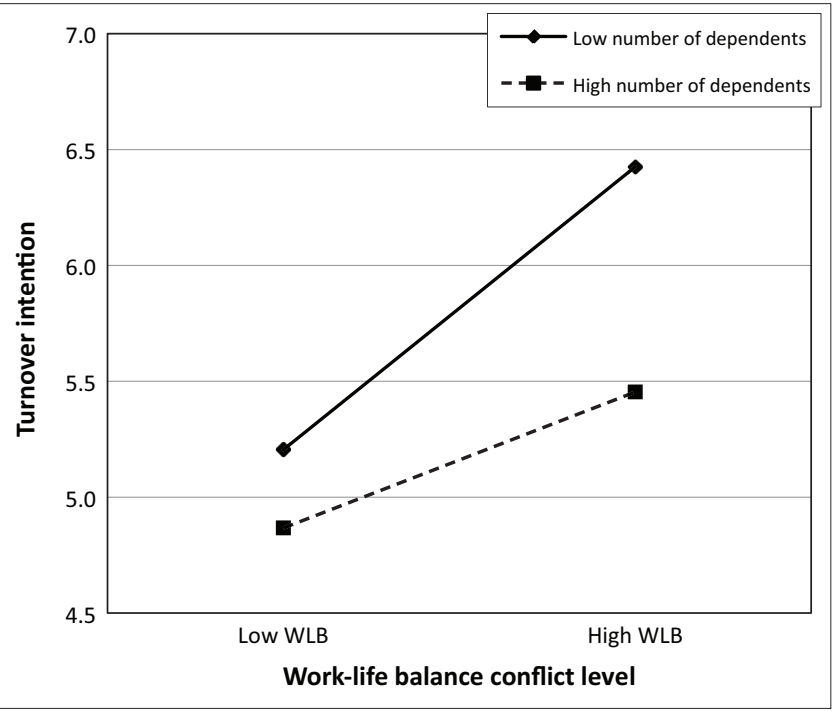

WLB, Work-life balance conflict.

FIGURE 3: Number of dependents as moderator on the work-life balanceturnover intention relationship (two-way interaction). larger at higher levels of WLBC, suggesting that those with family responsibilities might be less likely to quit than their counterparts. This is in line with other studies, for example by Almalki, FitzGerald and Clark (2012), who found lower intent to quit for those with children, and by Deery (2008), who found the number of dependent children to be an important moderator of the work-life balance. It seems that those with more children might be more risk averse, and that even if they experience higher levels of work-life balance conflict they may be more likely to stick it out in a job.

H1.d: The relationship between an increase in WLBC and intent to quit is strengthened under conditions of higher social support.

Social support is included here as a measure of the external context that an individual experiences as an employee. The WLBC-social support interaction term is found to be significantly related to turnover intentions $(p=0.014)$. Figure 4 illustrates this relationship. At lower levels of WLBC, individuals with greater social support report being more likely to quit, and this is the same for higher levels of WLBC, although the difference between those with higher and lower levels of social support is greater at higher levels of conflict.

The significance of this relationship suggests that social support is an important enabler of exit for individuals experiencing higher levels of WLBC. The null hypothesis is rejected. This finding is also in line with various studies which found social support to be a moderator in the prediction of turnover intentions (see Haar, Roche \& Taylor 2012). The fact that many studies have not found a moderating effect for social support (Haar 2004; Makola, Mashegoane \& Debusho 2015), suggests the importance of context in the determination of these relationships. This result contributes to the growing body of literature, indicating that under the conditions investigated by this study, this moderating effect holds.

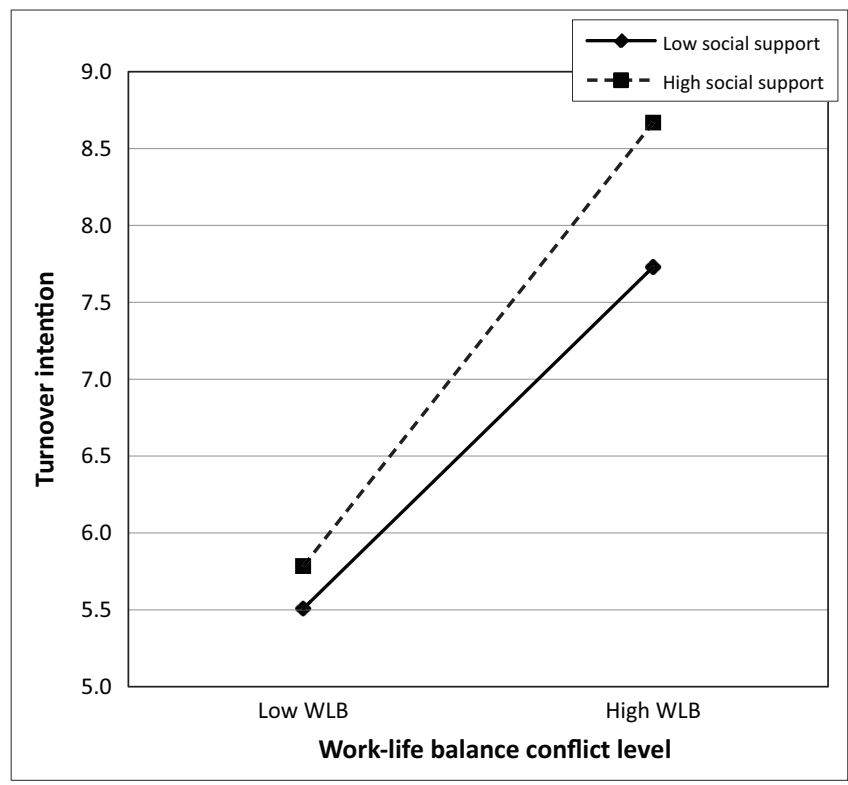

WLB, Work-life balance conflict.

FIGURE 4: Social support as a moderator of the work-life balance-turnover intention relationship (two-way interaction). 
H1.e: The relationship between an increase work-life balance conflict and intent to quit is weakened at higher levels of engagement.

The interaction term for engagement is not significant ( $p=0.152)$, suggesting that work engagement has little influence on reducing an individual's intent to quit at both low and high levels of work-life conflict. Figure 5 shows that individuals with a lower engagement report being more likely to quit at both high and low levels of WLBC, although the difference between these employees and those with higher reports of engagement is slightly narrowed at higher levels of WLBC. These results are similar to those of Naicker (2013) who found engagement to not moderate turnover intentions predictions.

H1.f: The relationship between increases in WLBC and intent to quit is strengthened at higher levels of stress.

Individuals with higher levels of stress (Figure 6) are not found to be significantly more likely to quit at higher levels of WLBC $(p=0.989)$. Individuals with higher stress are more likely to quit at both low and high levels of WLBC, but there is little difference between these and those experiencing lower levels of stress. Although a direct relationship has been found between stress and turnover intentions (Cropanzano, Rap \& Bryne 2003; Moore 2000), in this context the relationships between withdrawal cognitions and both WLBC and levels of stress seem to be independent of each other.

H2: Job satisfaction mediates the relationship between work-life balance and turnover intentions in this context.

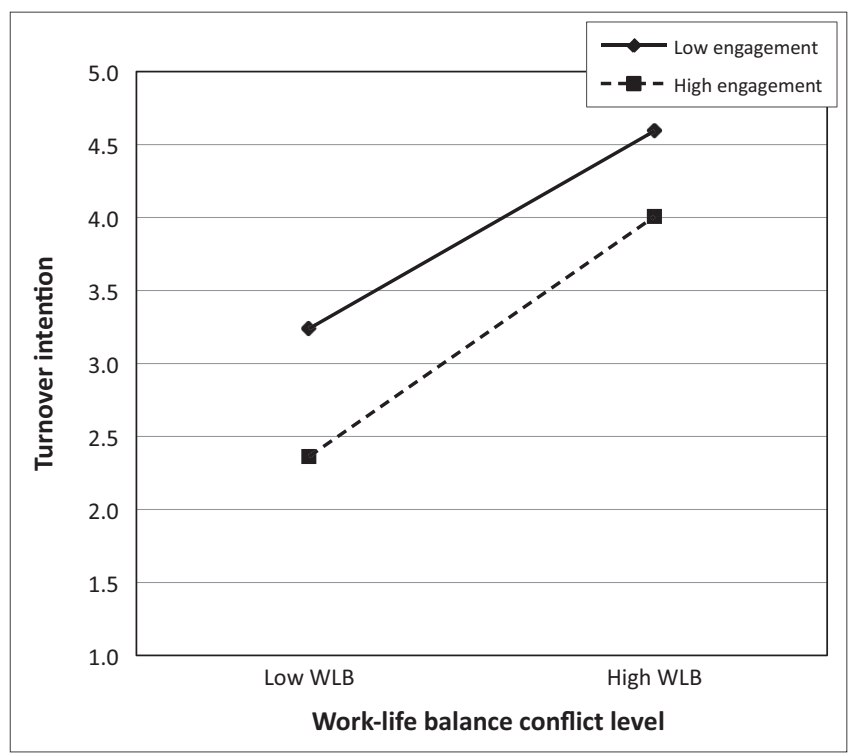

WLB, Work-life balance conflict.

FIGURE 5: Engagement as a moderator on the work-life balance-turnover intentions relationship (two-way interaction).
In order to test the mediation effect between WLBC and turnover intentions, the Hayes test of mediation was applied. The results are shown in Table 4 . The size of the indirect effect of WLBC on turnover intentions through job satisfaction is weaker than its direct effect, and insufficient evidence is found to support the mediation hypothesis. The null hypothesis is therefore not rejected.

The implication of this result is that WLBC is a direct influence on turnover intentions that does not have to act through the job satisfaction channel to increase turnover intentions. The lack of a mediating role for job satisfaction in the relationship between WLBC and turnover intentions is consistent with other work by Özbağ and Ceyhun (2014) who found no mediating effects of job satisfaction on the relationship between family-to-work conflict and turnover intentions in the Turkish context, in a study on marine pilots. This finding contrasts with findings of a partial mediating effect on job satisfaction on the relationship between work-life balance and turnover intention in Malaysian Higher Education institutions (Noor 2011), and a fully mediated relationship in the context of industrial employees in Iran (Fayyazi \& Aslani 2015) and healthcare workers in New Zealand (Riley 2006). Is this sample in some way atypical of others, in that the studying process (while working) might lend some robustness of individuals to $\mathrm{WLBC}$, at least to the pressures related to withdrawal cognitions? To test whether the effect of education within this sample would weaken the relationship between WLBC and turnover intentions, further within-sample testing was performed, and this is reported as follows.

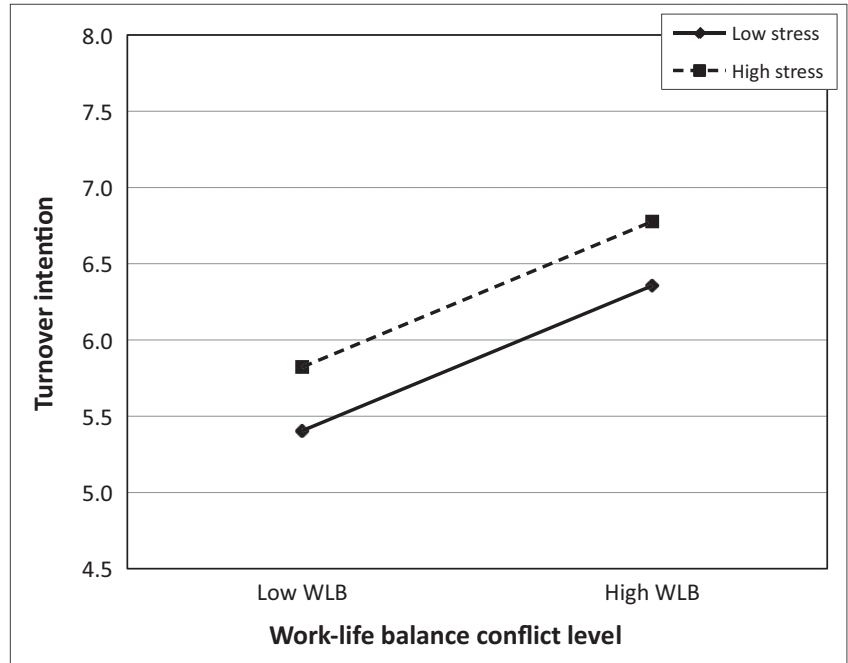

WLB, Work-life balance conflict.

FIGURE 6: Stress as a moderator on the work-life balance-turnover intention relationship (two-way interaction).

TABLE 4: Mediation results - total and indirect effects of Hypothesis 2.

\begin{tabular}{|c|c|c|c|c|c|c|c|c|c|}
\hline \multirow[t]{3}{*}{ Variable } & \multirow[t]{3}{*}{ Effect } & \multirow[t]{3}{*}{ Standard error } & \multirow[t]{3}{*}{$t$} & \multirow[t]{3}{*}{$p$} & \multicolumn{2}{|c|}{ Confidence interval } & \multicolumn{3}{|c|}{ Bootstrapped } \\
\hline & & & & & \multirow[t]{2}{*}{ Lower } & \multirow[t]{2}{*}{ Upper } & \multirow[t]{2}{*}{ Standard error } & \multicolumn{2}{|c|}{ Confidence interval } \\
\hline & & & & & & & & Lower & Upper \\
\hline Total effect of $X$ on $Y$ & 0.4488 & 0.0501 & 8.9600 & 0.0000 & 0.3502 & 0.5473 & - & - & - \\
\hline Direct effect of $X$ on $Y$ & 0.3023 & 0.0431 & 7.0163 & 0.0000 & 0.2175 & 0.3872 & - & - & - \\
\hline Indirect effect of $X$ on $Y$ : Job Satisfaction & 0.1464 & - & - & - & - & - & 0.0313 & 0.0880 & 0.2095 \\
\hline
\end{tabular}




\section{Post hoc testing}

A further test was performed to ascertain the effect of the interaction of WLBC and prior studies on intent to quit. Although individuals with higher education have higher turnover intentions, and although this difference seems to be larger at higher levels of WLBC (Figure 7), this difference is not significant in testing. This test was considered to be appropriate in order to gauge the potential influence of educational attainment for this cohort who were undertaking studies. The lack of a moderating effect on education accords with the results of a study by Du Plooy and Roodt (2013) in which education levels were not found to be a moderator in the prediction of turnover intentions, unlike the results of a study by Bester (2012), which found that they did.

Most respondents (71\%) fell into the age group 20-35 years, with most having a school leaving certificate as their highest qualification. Those with other qualifications seem to be a minority, and this result suggests that having a prior qualification does not differentiate an individual from the rest of the cohort in terms of their WLBC-withdrawal cognitions relationship.

\section{Limitations}

Certain limitations of the study need to be acknowledged. Firstly, this research was limited to one university and one geographic region, namely Gauteng. Results may be generalised only to contexts that are similar to this one. A cross-sectional study design was used, which has certain limitations as it cannot show which relationships are increasing or decreasing in their associations over time. The most important limitation of this study is that the methods applied here cannot be used to ascribe causality. This is a typical limitation of non-experimental research. Nevertheless, these results are taken to be a valid reflection of the net relationships between tested variables that manifest across the sample.

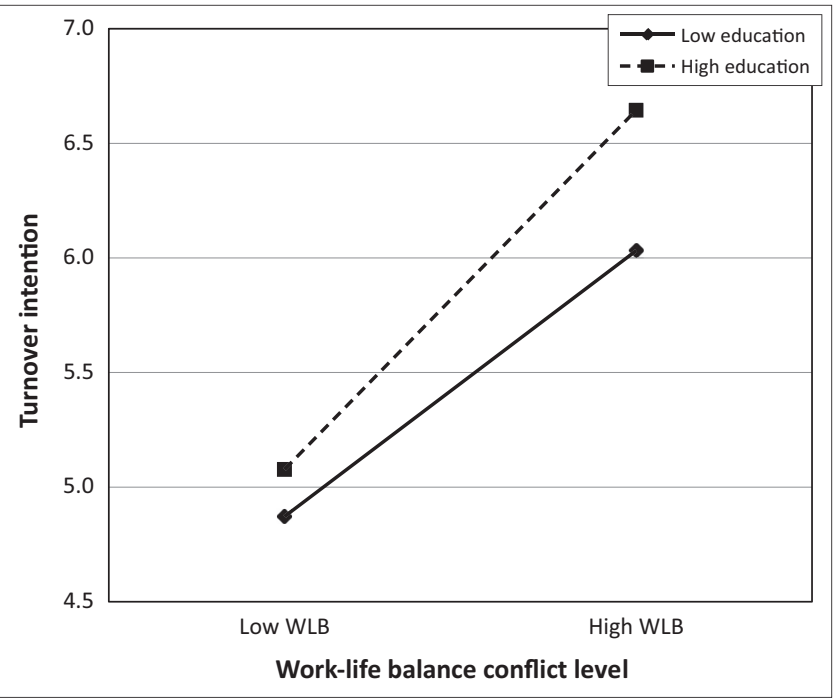

WLB, Work-life balance conflict.

FIGURE 7: Education levels as a moderator on the work-life balance-turnover intention relationship (two-way interaction).

\section{Practical implications}

The findings of this study have practical implications for various organisations regardless of industry. From this study, findings revealed that if work-family conflict is reduced among employees, there would be a reduction in the turnover intention levels of employees. For this reason, policies should be offered that look into ways that they could buffer the effects of work-life conflict, as well as the influence that dependent children have on employees' intentions to quit which would aid organisations in the retention of their employees.

A second implication is that turnover intentions can be alleviated by organisations when the impact of social support is taken into consideration. Findings have revealed that high levels of social support influence an employee's decision to stay within the organisation.

\section{Conclusion and recommendations for practice and further research}

The objective of this study was to test certain boundary conditions of theory that predicts certain relationships between WLBC and withdrawal cognitions. In so doing, it sought to quantify the moderating role of a host of demographic influences on the relationship between WLBC and withdrawal cognitions in the South African context. This context is taken to be particularly important in the study of employee retention, particularly given the life-changing opportunities offered by tertiary studies. Dependent children and social support were found to influence the focal relationship, in different directions. Whereas those with more dependent children might be less able to withdraw from an employment relationship, those with more social support seem to experience the opposite which has been stressed by Kahumuza and Schlechter (2008) who identify the critical role that social support plays in influencing the rate at which workers quit their organisations.

This is in support of Eisenberger, Fasolo and Davis-LaMastro (1990) who found that a situational variable such as social support could either strengthen or weaken the way conflict is perceived and can be seen in the manner in which an individual attempts to cope with conflict. However, this is in contradiction with a study conducted in a German context where employees were found to be less likely to have turnover intentions when experiencing work-to-family conflict or family-to-work conflict if they experience high levels of social support (Nohe \& Sonntag 2014). The authors pose the argument that social support can intercede between the negative evaluations that may occur between the various spheres of work-life balance and turnover intentions.

Therefore, the findings reveal the importance of context in the determination of cases where social support can prevent negative assessments about the workplace in which individuals are experiencing high levels of conflict between their work and family spheres. 
Age, gender, engagement and stress are not found to moderate the focal relationship, and satisfaction is not found to mediate it. These findings raise important questions about the pressures experienced by individuals who are working and attending evening degree classes in this context at this time. We suggest here that individuals might enter a period of 'stasis', or stability in their associations between job satisfaction and turnover intentions, whereas while they are studying, they are less likely to intend to quit, even when dissatisfied with their work. This would be an explanation for why these relationships do not reflect those expected in the general working context. We encourage further research to explore other explanations.

It might be that individuals who undertake degree studies enter this 'period of stasis', in which even the influence of age, gender, engagement and stress does not substantively add to, or subtract from, the influence of WLBC on withdrawal intentions. It might be that the pressures of family life steel an individual to deepen this state of stasis, perhaps to 'see it out', perhaps intensifying the perseverance of an individual. It is only social support networks, however, that seem to weaken this stasis effect, perhaps lowering the stakes of leaving a job for those holding out to finish their degree studies.

These results contribute to the literature on work-life conflict by offering evidence of under what conditions those seeking to study while working are more vulnerable to WLBC. This work also contributes to a longstanding body of literature in the South African context that has sought to understand the specific determinants of intent to quit across different contexts, for example that by Stanz and Greyling (2010).

It is concluded that this cohort of students, who invest their evenings in degree studies while working, may exist as an important subset of working adults. Given their need for perseverance, even while experiencing higher WLBC because of their studies, further research should seek to better understand this phenomenon we identify here, of stasis, or a robustness to the negative influences that are typically expected to manifest in general working contexts.

We therefore suggest that further research apply causal research designs to replicate our work, and to extend it to other contexts of study of work-life conflict at the nexus of employment, evening degree studies and family responsibilities. We believe that the findings of such research, if applied by societal stakeholders, can make a difference in the lives of these people.

\section{Acknowledgements Competing interests}

The authors have declared that no competing interests exist.

\section{Author's contributions}

J.A. conceptualised the research, performed the statistical analysis and wrote up the initial work. C.W.C. contributed to the conceptualisation and to the writing up of the manuscript for journal submission.

\section{Funding information}

This research received no specific grant from any funding agency in the public, commercial, or not-for-profit sectors.

\section{Data availability statement}

The University of the Witwatersrand Ethics Clearance was granted on condition of data confidentiality.

\section{Disclaimer}

The views and opinions expressed in this article are those of the authors and do not necessarily reflect the official policy or position of any affiliated agency of the authors.

\section{References}

Almalki, M., FitzGerald, G. \& Clark, M., 2012, 'The relationship between quality of work life and turnover intention of primary health care nurses in Saudi Arabia', BMC Health Services Research 12(1), 314. https://doi.org/ 10.1186/1472-6963-12-314

Avanzi, L., Fraccaroli, F., Sarchielli, G., Ullrich, J. \& Van Dick, R., 2014, 'Staying or leaving: A combined social identity and social exchange approach to predicting employee turnover intentions', International Journal of Productivity and Performance Management 63(3), 272-289. https://doi.org/10.1108/ IJPPM-02-2013-0028

Bester, F., 2012, 'A model of work identity in multicultural work settings', PhD thesis, University of Johannesburg.

Bothma, C. \& Roodt, G., 2013, 'The validation of the turnover intention scale', SA Journal of Human Resource Management 11(1), 1-12. https://doi.org/10.4102/ sajhrm.v11i1.507

Carlson, D., Kacmar, M., Wayne, J. \& Grzywacz, J., 2006, 'Measuring the positive side of the work-family interface: Development and validation of a work-family enrichment scale', Journal of Vocational Behavior 68(1), 131-164. https://doi. org/10.1016/j.jvb.2005.02.002

Chinomona, R., Chinomona, E. \& Joubert, P., 2013, 'Perceptions of equity and organisational commitment in the Zimbabwean hospitality industry: Implications for HR managers or employers', South African Journal of Labour Relations 37(2), 118-132.

Çilan, Ç.A. \& Can, M., 2014, 'Measuring factors effecting MBA students' academic performance by using categorical regression analysis: A case study of institution of business economics, Istanbul University', Procedia-Social and Behavioral Sciences 122, 405-409. https://doi.org/10.1016/j.sbspro.2014.01.1362

Clark, S., 2000, 'Work/family border theory: A new theory of work/family balance', Human Relations 53(6), 747-770. https://doi.org/10.1177/0018726700536001

Coetzee, M. \& Martins, N., 2007, 'Organisational culture, employee satisfaction, perceived leader emotional competency and personality type: An exploratory study in a South African engineering company', SA Journal of Human Resource Management 5(2), 20-32. https://doi.org/10.4102/sajhrm.v5i2.116

Cotton, J. \& Tuttle, J., 1986, 'Employee turnover: A meta-analysis and review with implications for research', Academy of Management Review 11(1), 55-70.

Cropanzano, R., Rupp, D. \& Byrne, Z., 2003, 'The relationship of emotional exhaustion to work attitudes, job performance, and organizational citizenship behaviors', Journal of Applied Psychology 88(1), 160. https://doi.org/10.1037/0021-9010.88.1.160

Deery, M., 2008, 'Talent management, work-life balance and retention strategies', International Journal of Contemporary Hospitality Management 20(7), 792-806. https://doi.org/10.1108/09596110810897619

Dockel, A., Basson, J. \& Coetzee, M., 2006, 'The effect of retention factors on organisational commitment: An investigation of high technology employees', SA Journal of Human Resource Management 4(2), 20-28.

Du Plooy, J. \& Roodt, G., 2013, 'Biographical and demographical variables as moderators in the prediction of turnover intentions', SA Journal of Industrial Psychology 39(1), 01-12. https://doi.org/10.4102/sajip.v39i1.1070

Edwards, J. \& Rothbard, N., 2000, 'Mechanisms linking work and family: Clarifying the relationship between work and family constructs', Academy of management review $25(1), 178-199$.

Eisenberger, R., Fasolo, P. \& Davis-LaMastro, V., 1990, 'Perceived organizational support and employee diligence, commitment, and innovation', Journal of Applied Psychology 75(1), 31. https://doi.org/10.1037/0021-9010.75.1.51

Fatoki, O., 2015, 'Gender, academic major and the love of money by university students in South Africa', Gender and Behaviour 13(1), 6632-6639. 
Fayyazi, M. \& Aslani, F., 2015, 'The impact of work-life balance on employees' job satisfaction and turnover intention; the moderating role of continuance commitment', International Letters of Social and Humanistic Sciences 51, 33-41. https://doi.org/10.18052/www.scipress.com/ILSHS.51.33

Field, A., 2000, Discovering statistics using SPSS for Windows: Advanced techniques for beginners, Introducing Statistical Methods Series, Sage, London.

Goldman, G. \& Callaghan, C.W., 2015, 'A holistic synthesis of the organisation theories', Journal of Intercultural Management 7(4), 5-19.

Greenhaus, J. \& Beutell, N., 1985, 'Sources of conflict between work and family roles', Academy of Management Review 10(1), 76-88. https://doi.org/10.5465/ amr.1985.4277352

Greenhaus, J., Collins, K. \& Shaw, J., 2003, 'The relation between work-family balance and quality of life', Journal of Vocational Behavior 63(3), 510-531.

Grzywacz, J. \& Carlson, D., 2007, 'Conceptualizing work-family balance: Implications for practice and research', Advances in Developing Human Resources 9(4), 455-471. https://doi.org/10.1177/1523422307305487

Gujarati, D.N. \& Porter, D. C (2009). Basic Econometrics. London: McGraw Hill Gujarati, D., 2011, Econometrics by example, Palgrave Macmillan, Hampshire.

Haar, J., 2004, 'Work-family conflict and turnover intention: Exploring the moderation effects', New Zealand Journal of Psychology 33(1), 35-39.

Haar, J., Roche, M. \& Taylor, D., 2012, 'Work-family conflict and turnover intentions of indigenous employees: The importance of the whanau/family for Maori', The International Journal of Human Resource Management 23(12), 2546-2560. https://doi.org/10.1080/09585192.2011.610344

Haslam, D., Filus, A., Morawska, A., Sanders, M. \& Fletcher, R., 2015, 'The WorkFamily Conflict Scale (WAFCS): Development and initial validation of a self-report measure of work-family conflict for use with parents', Child Psychiatry \& Huma Development 46(3), 346-357.

Hayes, A., 2013, PROCESS SPSS Macro [Computer software and manual]. Retrieved from http://afhayes.com/introduction-to-mediation-moderation-andconditional-process-analysis.html [Google Scholar].

Hellman, C.M., 1997., Job satisfaction and intent to leave', The Journal of Social Psychology, 137(6), 677-689.

Holgersson, H.E.T., Nordström, L. \& Öner, Ö., 2014, 'Dummy variables vs. category wise models', Journal of Applied Statistics 41(2), 233-241. https://doi.org/ 10.1080/02664763.2013.838665

Jacobs, E. \& Roodt, G., 2008., Organisational culture of hospitals to predict turnover intentions of professional nurses', Health SA Gesondheid (Online), 13(1), 63-78.

Jogee, R., Callaghan, N. \& Callaghan, C.W., 2018, 'Student acculturation in the context of "feesmustfall"', Journal of Higher Education 32(2), 122-142. context of "feesmustfall"', Journal
https://doi.org/10.20853/32-2-1645

Kahumuza, J. \& Schlechter, A., 2008, 'Examining the direct and some mediated relationships between perceived support and intention to quit', Management Dynamics: Journal of the Southern African Institute for Management Scientists 17(3), 2-19.

Kantor, J. \& Crosser, A., 2016, 'High turnover costs way more than you think', The Huffington Post. Retrieved from http://www.huffingtonpost.com/julie-kantor/ high-turnover-costs-way-more-than-you-think_b_9197238.html

Kinnear, L. \& Sutherland, M., 2000, 'Determinants of organisational commitment amongst knowledge workers', South African Journal of Business Management 31(3), 106-112.

Kruger, D., 2003, 'Integrating quantitative and qualitative methods in community research', The Community Psychologist 36, 18-19.

Makola, L., Mashegoane, S. \& Debusho, L., 2015, 'Work-family and family-work conflicts amongst African nurses caring for patients with AIDS', Curationis 38(1), 1-8.

Martin, A. \& Roodt, G., 2008, 'Perceptions of organisational commitment, job satisfaction and turnover intentions in a post-merger South African tertiary institution', SA Journal of Industrial Psychology 34(1), 23-31. https://doi. org/10.4102/sajip.v34i1.415

Mincer, J. \& Jovanovic, B., 1979, 'Labor mobility and wages (No. w0357)', Nationa Bureau of Economic Research. Retrieved from https://www.nber.org/papers/ w0357.pdf

Moore, F., 2007, 'Work-life balance: Contrasting managers and workers in an MNC', Employee Relations 29(4), 385-399.

Moore, J.E., 2000, 'One road to turnover: An examination of work exhaustion in technology professionals', MIS Quarterly 24(1), 141-168. https://doi. org/10.2307/3250982

Motowidlo, S., Packard, J. \& Manning, M., 1986, 'Occupational stress: Its causes and consequences for job performance', Journal of Applied Psychology 71(4), 618.

Naicker, K., 2013, 'Employee engagement as the moderator of the relationship between psychological contract breach and perceived supervisor support; and the intention to quit', PhD thesis, University of Pretoria.
Nakigudde, J., Seggane, M., Airaksinen, E. \& Agren, H., 2009, 'Adaptation of the multidimensional scale of perceived social support in a Ugandan setting', African Health Sciences 9(2), S35-S41.

Nohe, C. \& Sonntag, K., 2014, 'Work-family conflict, social support, and turnover intentions: A longitudinal study', Journal of Vocational Behavior 85(1), 1-12. https://doi.org/10.1016/j.jvb.2014.03.007

Noor, K., 2011, 'Work-life balance and intention to leave among academics in Malaysian public higher education institutions', International Journal of Business and Social Science 2(11), 240-248.

Omotayo, F., 2015, 'Knowledge Management as an important tool in Organisationa Management: A Review of Literature', Library Philosophy and Practice 1, 1-23.

Oosthuizen, R., Coetzee, M. \& Munro, Z., 2016, 'Work-life balance, job satisfaction and turnover intention amongst information technology employees', Southern African Business Review 20(1), 446-467. https://doi.org/10.25159/1998-8125/6059

Özbağ, G.K. \& Ceyhun, G.Ç., 2014. 'Does job satisfaction mediate the relationship between work-family conflict and turnover? A study of Turkish marine pilots', Procedia-Social and Behavioral Sciences, 140, 643-649.

Papageorgiou, E. \& Callaghan, C., 2014, 'Resource scarcity and information technology Issues and trends among first-year accounting students', South African Journal of Higher Education 28(5), 1575-1592.

Papageorgiou, E., Callaghan, C., Coldwell, D. \& Joosub, T., 2014, 'Perceptions among professional Accounting students of self, job attractiveness and academic reputation', Journal of Accounting Research 28(1), 25-40.

Peltokorpi, V., Allen, D. \& Froese, F., 2015, 'Organizational embeddedness, turnover intentions, and voluntary turnover: The moderating effects of employee demographic characteristics and value orientations', Journal of Organizational Behavior 36(2), 2292-312. https://doi.org/10.1002/job.1981

Pradhan, G., 2016, Conceptualising work-life balance, Institute for Social and Economic Change, ISEC Working Paper 36, viewed 08 February 2019, from http://www.isec. ac.in/WP\%20368\%20-\%20Gayathri\%20Pradhan \%20-\%20Final.pdf.

Riley, D., 2006, 'Turnover intentions: The mediation effects of job satisfaction, affective commitment and continuance commitment', PhD thesis, University of Waikato, Hamilton, New Zealand.

Roodt, G., 2004, 'Turnover intentions', Unpublished document, Johannesburg University, Johannesburg.

Samuel, M. \& Chipunza, C., 2009, 'Employee retention and turnover: Using motivational variables as a panacea', African Journal of Business Management 3(9), 410-115.

Sarra, B., Benabou, D. \& Tabeti, H., 2013, 'The role of strategic human capital management in achieving the competitive advantage', Academic Journal of Interdisciplinary Studies 2(3), 361. https://doi.org/10.5901/ajis.2013.v2n3p361

Schilling, K., 2014, 'The relationship between job engagement, work interference with personal life, and turnover intentions', PhD thesis, Middle Tennessee State University, Murfreesboro, TN.

Stanz, K. \& Greyling, J., 2010, 'Turnover of nursing employees in a Gauteng hospital group', SA Journal of Industrial Psychology 36(1), 1-11. https://doi.org/10.4102/ sajip.v36i1.850

Stevens, S., 1946, 'On the theory of scales of measurement', Science 103(2684), 677-680. https://doi.org/10.1126/science.103.2684.677

Visser, D. \& Coetzee, S., 2005, 'Affective-cognitive consistency of attitude as a moderator of the job satisfaction-performance relationship', SA Journal of Industrial Psychology 31(3), 62-69.

Weiss, D., Dawis, R. \& England, G., 1967, Manual for the Minnesota Satisfaction Questionnaire, vol. 22, Work Adjustment Project, Industrial Relations Center, University of Minnesota, Minneapolis, MN.

Wilcox, S., 2010, 'Social relationships and PTSD symptomatology in combat veterans', Psychological Trauma: Theory, Research, Practice, and Policy 2(3), 175. $\mathrm{https} / / /$ doi.org/10.1037/a0019062

Wilson, K., 2009. A survey of employee engagement (Doctoral dissertation, University of Missouri--Columbia)

Wongpakaran, T., Wongpakaran, N. \& Ruktrakul, R., 2011, 'Reliability and validity of the multidimensional scale of perceived social support (MSPSS): Thai version', Clinical Practice and Epidemiology in Mental Health: CP \& EMH 7, 161. https://doi. org/10.2174/1745017901107010161

Yip, P. \& Tsang, E., 2007, 'Interpreting dummy variables and their interaction effects in strategy research', Strategic Organization 5(1), 13-30. https://doi.org/ 10.1177/1476127006073512

Zimet, G., Dahlem, N., Zimet, S. \& Farley, G., 1988, 'The multidimensional scale of perceived social support', Journal of Personality Assessment 52(1), 30-41. https://doi.org/10.1207/s15327752jpa5201_2 